\title{
RAZÓN Y EXPERIENCIA RELIGIOSA DE LOS JÓVENES EN LA POSTMODERNIDAD
}

Manuel Marzal S.J.

W n este simposio sobre los «Los jóvenes y el cambio frente al tercer milenion, me piden hablar sobre razón y experiencia religiosa en los jóvenes universitarios de la postmodernidad ante el nuevo milenio. Paso a exponer el sentido de los términos comenzando por la razón. Aunque los universitarios tengan la fe en la razón de la Ilustración, y aunque la universidad sea, sobre todo, una institución intelectual que muestra la gimnasia mental de tantas horas de clase en las que se comunican solo ideas, no debe olvidarse que la razón está hoy un tanto devaluada. Tampoco debe olvidarse que los jóvenes parecen valorar más sus sentimientos y su experiencia subjetiva que la capacidad intelectual; si es bueno que valoren lo emocional, es una lástima que sea a costa de lo intelectual. Conviene recorclar que Juan Pablo II en su última encíclica, Fides et Ratio, sobre el clásico tema de la relación entre fé y razón, hace una observación sobre el mundo actual que es válida también para el mundo juvenil. Según el Papa, en la actualidad

Tanto la fe como la razón se han empobrecido y debilitado una ante la otra. La razón, privada de la aportación de la Revelación, ha recorrida 
caminos secundarios que tienen el peligro de hacerle perder de vista su meta final. La fe, privada de la razón, ha subrayado el sentimiento y la experiencia, corriendo el peligro de dejar de ser una respuesta universal. Es ilusorio pensar que la fe, ante una razón débil, tenga mayor incisividad; al contrario, cae en el peligro de ser reducida a mito o superstición. Del mismo modo, una razón que no tenga ante si una fe adulta no se siente motivada a dirigit la mirada hacia la novedad y la radicalidad del ser. ${ }^{2}$

Llamo experiencia religiosa al modo de concebir a Dios y relacionatse con Él por el culto y la práctica ética. Supongo que los jóvenes tienen una experiencia religiosa diferente a la de sus padres por causa de respirar un mundo religioso distinto, pues en las últimas décadas ha habido un enriquecimiento y complejización de la teología católica y, a la par, una menor valoración de la Iglesia como institución, lo cual repercute en la experiencia religiosa de los jóvenes.

Al tratar de los jóvenes, es útil preguntarse si ellos forman una cultura. Creo que si, en ciertas sociedades, y más en la moderna urbano-industrial, pues la juventud se prolonga cada vez más y se asume más tarde el papel de adulto. Es una etapa de «transición» en la que se rompe no solo con la etapa de la niñez, por el lógico crecimiento, sino también con la vida de los adultos como modo de auto-afirmación y de ser diferente. Los adultos hablan a veces del «mito del joven»; yo lo he oído, por ejemplo, entre los religiosos, para recalcar el sentido comunitario de los jóvenes frente al individualismo de Ios mayores. Yo pienso que tal mito tiene la misma debilidad que el viejo mito del «buen salvaje», y así debe hacerse cierta desmitificación. En general, creo que los jóvenes no son mejores ni peores que los adultos, aunque, como no han tenido los «errores» de los adultos, se atreven a hablar con más 
seguridad; pero tienen oportunidades que ya no tienen muchos adultos $y$, desdeluego, viven un mundo cultural diferente y, así, hablan de modo diferente.

Hago ahora una referencia al tercer milenio. Es cierto que no se puede predecir sobre un espacio tan largo, como gusta a ciertos periodistas, para lo cual basta recordar lo poco comparable que son la vida política y religiosa del mundo en el año 1000 y en el 2000 que se acerca. Sin duda, por una parte, el siglo que termina y el que comienza serán diferentes por varias razones. Si una razón importante es el ritmo de los cambios tecnológicos, no conviene olvidar otras. Por ejempla, ya no existe en el mundo la gran amenaza de los dos bloques, capitalista y socialista, con visiones de la sociedad enfrentadas y con armas en la mano para imponer su propia visión; tampoco existe en el país la pequeña amenaza de conflictos periódicos con Ecuador, con una paz armada y una pequeña guerra cada cierto tiempo, Pero, por otra parte, el siglo que termina y el que empieza serán parecidos porque lo dificil no es cambiar las tecnologias, sino a los hombres y a sus valores, y porque, quizás, hoy somos menos optimistas sobre su cambio que nunca.

Antes de abordar el tema, quiero indicar por qué estudiar este tema y cómo. Es un tema que debe estudiarse porque es clave para conocer los cambios de la sociedad, que solo cambia cuando cambian los valores. Además, es un temá poco estudiado: personalmente, aunque me dedico a investigar el comportamiento religioso peruano, lo he estudiado únicamente de modo indirecto, como término de comparación de la religión de los adultos, por ejemplo, mi estudio de la imagen de Dios en Ayaviri;' sin embargo, han aparecido recientemente dos nuevos estudios, el de Juan Carlos Cortâzar 'y el de Luis Mujica."

En cuanto al cómo, yo presenté una hipótesis de trabajo en el encuentra sobre la relación Fe y Cultura de universidades de inspiración cristiana (Lima, 23-25 mayo de 1998), que tetomo y amplio, siempre como 
hipótesis de trabajo. Este carácter de hipótesis no es por simple modestia, sino porque la antropología, que estudia sobre todo culturas tradicionales, ha estudiado poco la juventud, pues en aquellas esta es casi solo una iniciación hacia la edad adulta. Recientemente, los antropólogos han comenzado a estudiar ciertos problemas juveniles que preocupan a los adultos, como la violencia de pandillas a la aparición de movimientos contraculturales (movimiento hippie, rock salvaje, entre otros). El trabajo tiene dos partes: la primera presenta y comenta dos estudios sobre el tema, y la otra expone mi hipótesis.

\section{Dos estudios empíricos}

Cortázar hace un estudio comparativo de jóvenes universitarios de Ciencias Sociales de la Universidad Nacional Mayor de San Marcos (UNMSM), de Arquitectura de la Universidad Nacional de Ingeniería (UNI) y de Medicina de la Universidad Peruana Cayetano Heredia (UPCH) entre 1990-1991. Sus principales hallazgos son:

\section{a) Autoidentificación religiosa}

Católicos: SNMSM (57.8\%), UNI (72.5\%) y UPCH (79.5\%); evangélicos: $3.2 \%, 7.3 \%$ y $5.3 \%$, respectivamente; otra religión, $2.2 \%, 2.3 \%$ y $2.6 \%$; no creyentes, $34.8 \%, 17.9 \%$ y $13.2 \%$. Los porcentajes de evangélicos y de otras religiones son bastante similares a los del último censo nacional, pero muy distintos en los no creyentes, lo que repercute en la mayoría católica.

\section{b) Atributo básico dado a Dios}

Es un poder protector que se siente tanto en las situaciones límite $(20 \%$, $38 \%$ y $39 \%$ ), como sucede entre los católicos populares, como en los momentos 
de depresión, soledad, e intranquilidad (35\%,23\% y 18\%), que parecen estar vinculados a las necesidades subjetivas del joven creyente.

\section{c) Devoción a los santos o imágenes, incluidas las de la Virgen María y Jesucristo}

Esta devoción no es cosa del pasado para los estudiantes, pues más de la mitad de cada grupo estudiado $(56 \%, 68 \%$ y $61 \%$ ) creen que los santos influyen en sus vidas, aunque es mayor, a diferencia de los católicos populares, el carácter ejemplar que de protección, excepta en el caso de la UNI. En la pregunta sobre qué espera recibir de los santos, si bien la protección tiene un rol central, «de forma similar a lo que sucede en la relación con Dios, el resultado del vínculo con los santos se manifiesta principalmente en la experiencia subjetiva (tranquilidad, paz, necesidad de ser escuchado)w. Es decir, que "tal "centro generador" se refiere, en el caso de los estudiantes, to tanto al ámbito de las necesidades materiales, sino al de las experiencias subjetivas»?

\section{d) Práctica religiosa (frecuente o esporádica)}

La oración personal $(96.2 \%, 95.4 \%$ y $88 \%)$ y la misa dominical $(79.8 \%$, $83.9 \%$ y $78.1 \%$ ) son las expresiones a las que se acude más y que pueden vivirse de modo más subjetivo, aunque las procesiones lo sean también en las dos universidades más frecuentadas por los sectores populares $(60,7 \%$ y $54,6 \%$, UNI y UNMSA, respectivamente) y no tanto en la UPCH (25.2\%).

\section{e) Actitud frente a la Iglesia}

Aparecen dos posturas opuestas ante la Iglesia: como institución: «[,...] predomina una actitud de indiferencia y lejanía, que incluye una critica severa 
que la considera rígida y yerticaly; como comunidad a la que se pertenece: «[...] manifiestan simpatía por una vivencia comunitaria que implique diálogo, cariño y orientación normativa. Esta simpatía coincide con la búsqueda de paz interior, tranquilidad y escucha que los estudiantes ponen de manifiesto reiteradamentes:

De estos cinco puntos se desprende que la religiosidad de los estudiantes se puede considerar protectora de parte de Dios y de los santos, como la del catolicismo popular, y subjetiva, pues la experiencia del individuo, particularmente emocional, es el criterio central para definir la validez de las prácticas y de las normas religiosas.

Mujica ha realizado dos estudios sobre valores de los cachimbos de la Pontificia Universidad Católica del Perú (PUCP) en los dos semestres delaño 1997.Parael primersemestre, recogeestos datos sobrevaloresteligiosos:

a) Identificación: católicos, $87 \%$; otra religión, 5\%; sin religión, $8 \%$.

b) Imagen de Dios: amigo o padre que ayuda, $32.5 \%$; fuerza presente en cada uno, $31 \%$; creador y origen de todo, $13.5 \%$.

c) Visión de la Iglesia: espacio de amor y de relaciones humanas, 35.7\%; diálog y y compromiso con los demás, $32.5 \%$; espacio de encuentro con Dios mediante sacramentos, $10.3 \%$.

d) Visión ética: lo bueno o lo malo depende de las circunstancias, 38\%; dc normas objetivas, $23 \%$; no se problematiza, no sabe o no contesta, $39 \%$.'

Para el segundo semestre, la información sobre religión es la siguiente:

a) Identificación: católicos, $89.1 \%$; evangelicos, $3.4 \%$; otra religión (incluidos testigos y mormones), $2.3 \%$; ninguna, $4.6 \%$. 
b) Imagen de Dios: amigo y padre, 36\%; fuerza presente en cada uno, $27.4 \%$; creador, $20.6 \%$.

c) Devoción a los santos: no tienen, 84.6\%; sí tienen, 15,6\%, donde se incluyen advocaciones de Jesús y de María.

d) Participación litúrgica: todas o casi todas las semanas, 40\%; rara vez, 40\%; solo en Navidad y Semana Santa, $9.1 \%$; solo en bautismos o matrimonios, $5.1 \%$; nunca, $5.1 \%$.

e) Visión de la Iglesia: espacio de amor y comprensión, 43.4\%; diálogo y compromiso con los demás, $31.4 \%$; encuentro con Dios por sacramentos, $16 \%$

f) Visión ética: lo bueno y lo malo depende las circunstancias, 38\%; de normas objetivas, $23 \%$; no delo subjetivo ni de lo objetivo, $25 \%$; no saben, $13 \%$."

Deambos estudios empíricos sepueden hacer ciertas generalizaciones.

1. Hay una gran mayoría de católicos, similar a la del promedio nacional, y una minoria poco relevante de no creyentes.

2. La imagen de Dios sigue siendo la del católico populat, aunque, quizás, más subjetiva y personal que la de aquel.

3. Los cachimbos, a diferencia de los católicos populares, tienen poca devoción alos santos.

4. La práctica religiosa, aunque alta en un sector, disminuye notablemente, lo que parece deberse a la ausencia de devociones que en el católico popular son la principal ocasión de práctica religiosa.

5. La Iglesia es percibida, más que como institución o depositaria dela salvación a través de los ritos, como espacio para la experiencia subjetiva y para el compromiso social. 
6. Lo ético se mide, al menos con una mayoría relativa, desde las circunstancias, lo que revela un relativismo ético y cierta crisis de las instituciones orientadoras de la moral."

En ambos informes, Mujica hace un estudio más amplio sobre valores. Las conclusiones del primer informe, de las que no difieren radicalmente las del segundo, ${ }^{12}$ son las siguientes:

1. Las condiciones familiares y económicas del joven son buenas: en el hogar goza de relativa estabilidad en el nivel afectivo y emocional; el joven se siente respaldado socialmente y cuenta con una seguridad económica.

2. En general, el joven se auto percibe como satisfecho de la vida y se siente feliz, en la medida que tiene mayor conciencia de sus capacidades y de haber logrado metas, esto significa que tiene una autoestima bastante elevada.

3. El valor más apreciado entre los jóvenes parece ser la libertad, en la medida en que son conscientes de su autonomía personal y de su relativa independencia, expresada en la manera de relacionarse con las personas de otro sexo, de otra generación y de las instituciones.

4. La igualdad es otro valor igualmente preciado. Consiste en el reconocimiento de las diferencias y en el respeto de ellas, las que se expresan en la tolerancia en el nivel de las relaciones de género, en el mundo religioso y en el político. La pluralidad parece ser otro rasgo de la valoración de los otros.

5. La responsabilidad parece ser otro valor expresado por los jóvenes, en la medida en que ponen en juego sus capacidades y el desarrollo personal, y tratan, asî, de prever las consecuencias de sus acciones en el ámbito individual y en las relaciones con otras personas. 
6, La participación del joven consiste, sobre todo, en la bưsqueda de espacios de expresión y de experiencias que le permitan subrayar la dimensión subjetiva sobre el mundo religioso.

7. La solidaridad es un valor que no abandona el perfil del joven en la medida en que la búsqueda de realización personal no agota la dimensión colectiva. Sin embargo, la realización privada individual es preferida a la participación y el compromiso social.

8. La conducta indefinida y los casos de dependencia probablemente impliquen el desconocimiento de las situaciones y el temor de participar en diversas instituciones.

Aunque no se puede dudar de los datos empíricos recogidos por Mujica, que se consolidaron con la opinión de ugrupos focalesu de cachimbos que quisieron colaborar, debe recordarse la limitación de la encuesta para investigar los valores. Es sabido que los antropólogos de la religión investigan los ritos, la organización religiosa y hasta las creencias, pero tienen desconfianza en los estudios sobre ética, especialmente en los hechos a partir de encuestas, aun las respondidas por escrito. Además, dichas conclusiones sobre los valores del cachimbo me parecen demasiado optimistas, quizás pueda deberse al momento de aplicación de la encuesta, es decir, el día de la matrícula, poco después del esperado ingreso a la universidad. Por mi experiencia y mis conversaciones con alumnos hace más de treinta años, creo que esas conclusiones no representan al universitario promedio. Este dene una personalidad más débil y sus valores religiosos están amenazados por la secularización del ambiente universitario, en el que muchos aparecen como si no creyeran o como si, para ellos, la pregunta religiosa no fuera importante $\mathrm{o}$, si lo es, no se habla de ella en público. Esta visión pesimista es compartida 
por asesores del Centro de Asesoría Pastoral Universitaria (CAPU) y por otros profesotes preocupados por lo religioso.

\section{Hipótesis sobre el joven peruano y la religión}

Al presentar mi hipótesis, comienzo por referirme a los cambios del país, de la Iglesia y del horizonte cultural que han vivido los jóvenes peruanos. Se diria que los jóvenes crecieron en el desconcierto provocado por cambios tan rápidos. Los cambios del Perú han sido estos: el país se ha modernizado y urbanizado; ha habido una revolución militar peculiar que produjo grandes esperanzas iniciales y frustraciones finales; se desató el tertorismo de Sendero Luminoso y el Movimiento Revolucionario Túpac Amaru, aún no del todo superado, y en la calle se impuso la violencia de cada día; la caída de los socialismos de estado ha consolidado un neoliberalismo competitivo que actecienta las diferencias sociales; los medios de comunicación trafican con el sexo, la violencia y el ultra realismo, y se han convertido, para muchos, en productores de sentido; en esta sociedad, bombardeada por tantos mensajes, se vive cierta trivialización de la palabra y parece cada vez más dificil, como quiere San Ignacio de Loyola en sus Ejercicios espinituales, sentir y gozar de las cosas internamente,

También la Iglesia ha tenidos grandes cambios, que, de algún modo, gravitan sobre los jóvenes. Estos no han sentido la fe de muchos de la generación de sus padres sobre la doctrina social de la Iglesia como alternativa entre el capitalismo y el socialismo, ni la esperanza sobre el Concilio Vaticano II y su versión latinoamericana en la Conferencia Episcopal de Medellin, ni el entusiasmo generado por la teología de la liberación. En cambio, han sido testigos del desconcierto del postconcilio, la secularización crecienté, 
la inestabilidad del matrimonio y de la vida consagrada, la multiplicación de las sectas; el relativismo religioso y ético, la reacción fundamentalista, las respuestas personales eclécticas, y la expansión del agnosticismo.

Muchos de estos rasgos denotan un nuevo horizonte cultural: la postmodernidad. Aunque no se sabe bien qué sea y que aún no tenga un nombre propio, sino una preposición de relación temporal con lo pasado, afirma el fin del mundo moderno. Ha terminado un mundo basado en el imperio de la razón, la ciencia y la tecnología que prometió el progreso para todos y trajo las dos guerras más catastróficas de la historia. González Carvajal describe así la postmodernidad y sus valores, más o menos explícitos: fin de la idea de progreso $y$ final de la historia; hedonismo, que deja el mito de Prometeo y acepta el de Narciso; declive de la razón y supervaloración del sentimiento subjetivo; fragmentación del individuo con lógicas varias y contradictorias; aparición del hombre ligbt, renacimiento religioso y retorno de los brujos. ${ }^{\text {i4 }}$

Ante este mundo cambiado y postmoderno, équé caminos religiosos toman los jóvenes? No pocos, ante la secularización de la cultura que acentúa el relativismo religioso, reprimen la pregunta del sentido de la vida y viven no el ateísmo, que parece ser un género en extinción, sino un agnosticismo funcional. Essta represión no se mira como definitiva, sino como temporal, aunque se trate de un udespués» o un umañanay bastante indeterminados. Respecto de esta situación, Enrique Luengo señala lo sigueinte: "Comienza a transitar en la sociedad un tipo de hombre que parece no angustiarse de la desaparición de Dios. Vive instalado más o menos perfectamente en la finitud. No vive la nostalgia de lo totalmente otro (Horkheimer), ni la angustia kirkergaardiana de la existencia. Su tonalidad víal es la suave, quizás melancólica, indiferencias,." 
Sin embargo, la mayoría de los jóvenes se plantean, de modo más o menos consciente, la pregunta y optan por uno de estos tres caminos: seguir por cierta inercia en la Iglesia cultural, que es parte de la identidad colectiva; insertarse activamente en la Iglesia renovada y pluralista; o situarse claramente al margen de la Iglesia. Paso a exponer cada camino.

\subsection{Permanencia en la Iglesia cultural}

Creo que la mayoria de los jóvenes seguirán tal camino, aunque a menudo después de un periodo de abandono de la práctica religiosa y, aun, de indefinición de la propia postura religiosa. Tal camino, aunque puede parecer más cultural que religioso, supone una decisión personal y entraña cierta reconciliación con la cultura familiar tras un periodo de ruptura para a firmarse o por no ser capaz de oponerse a una cultura juvenil más secular y libre de restricciones. Lo cierto es que muchos jóvenes, que, según Cortázar, son hijos no siempre autoreconocidos del catolicismo popular en su estructura básica, acuden a la Iglesia en momentos importantes de la vida (ritos de paso de bautismo, confirmación y matrimonio), de la liturgia (Navidad o Semana Santa) o de la vida social en un país ceremonialmente católico. Además, esta práctica esporádica del catolicismo popular supone una visión religiosa que es suficiente para responder la pregunta religiosa del sentido de la vida y que no se contradice con la visión profesional o politica que se vive en la etapa adulta en la que se ingresa. Es sabido que el catolicismo popular tiene un gran poder de adaptación y permanece casi idéntico a si mismo, aunque carnbien el contexto políico o cultural en el que florece. 


\subsection{Opción por una Iglesia renovada y pluralista}

Frente a la permanencia en la Iglesia cultural, una creciente minoría asume una verdadera militancia y se inserta en las udistintas moradas" de una Iglesia pluralista. Tales moradas son cuatro:

\section{a) Grupos juveniles}

Estos han existido siempre y más desde el nacimiento de la Acción Católica. Los jóvenes que los integran cultivan distintos aspectos de la vida cristiana, como conocimiento de la Biblia, participación en la liturgia a través de la música y el canto, distintas formas de solidaridad con el mundo marginal, etc. Tales movimientos juveniles, aunque cuenten a menudo con sacerdotes, religiosos o religiosas como asesores, suponen formas de autogobierno y privilegian el intercambio de experiencias personales.

\section{b) Comunidades de base}

Son grupos más recientes que entrañan una opción por los pobres y por la justicia social, que el omnipresente neoliberalismo hace más necesaria. Surgieron a raíz de Medellín, se inspiraron en la teología de la tiberación y alimentaron proyectos politicos de izquierda. A pesar de los avatares de dicha teologia y de dichos proyectos, las comunidades de base significan un camino religioso para los jóvenes preocupados por una espiritualidad más biblica y una defensa de las formas de solidaridad y de los derechos humanos.

\section{c)Nuevos movimientos eclesiales}

Son los grupos más recientes; han nacido con gran vigor y dinamismo en medio del secularismo y del relativismo religioso y ético, los que, así como 
su enfasis en la dimensión específicamente religiosa, tienen cierto sabor fundamentalista. De cualquier modo, ejercen incudable atracción, pues muchos jóvenes descubren en ellos una exigente vida ritual y apostólica, y una respuesta a las propias inseguridades en un discurso teológico coherente. Tales movimientos, como los otros caminos señalados, no son solo juveniles, sino que abarcan otros sectores de la Iglesia, donde significan una fuerza nueva en el postconcilio. El Papa, en un encuentro mulfitudinario en la plaza de San Pedro de Roma el 30 de mayo de 1998, ha querido legitimar y orientar a 56 movimientos de todo el mundo, como Comunión y Liberación, los Focolares, el Movimiento Neocatecumenal, las Comunidades del Arca, el Sodalitium Christianae Vitae, entre otros. En su discurso, el Papa dijo:

Vosotros aqui presentes sois la prueba tangible de esa efusión del Espíritu. Hoy a todos vosotros reunidos [...] os quiero gritar: [Abrios con docilidad a los dones del Espíritul [...] ¡No olvidéis que cada carisma es dado para el bien comúnl [.... Por su naturaleza, los carismas son comunicativos y hacen nacer [.... a los "movimientos". Su nacimiento y su difusión han traido a la vida de la Iglesia una inesperada novedad [....]. Esto no ha dejado de suscitar interrogantes, sinsabores y tensiones, algunas veces ha comportado presunciones e intemperancias, por un lado; y no pocos prejuicios y reservas, por el otro [...]. Hoy, ante vosotros, se abre una etapa nueva: la de la madurez eclesial. ${ }^{10}$

\section{d) Cristianos en un mundo postmoderno}

Dentro de grupos a fuera de ellos, hay en la actualidad jóvenes que piensan que la postmodernidad, nos guste o no nos guste, está preserite en el mundo, y que ella, a pesar de sus riesgos, ofrece oportunidades que deben ser asumidas 
con coraje y con una visión providencial de la historia conducida por Dios. Entre las oportunidades de la postmodernidad, García Orso señala las siguientes: crítica de la sociedad opresora y deshumanizante; la valoración de la experiencia personal; la recuperación de dimensiones olvidadas de la persona, como el sentimiento y la vida frente a la razón y el trabajo (del bomo rationalis al bomo sentiens y del bomo faber al bomo vivens); la apertura a los otros; y la búsqueda, con ellos, de una verdad que no se impone. García Orso concluye: «Pienso que la post modernidad nos invita a los cristianos a madurar una triple experiencia: la experiencia de la realidad, la experiencia de los otros y la experiencia de Dios. La realidad como acceso al Misterio último. Dios como Amor entregado a los hombres, y los otros en cuanto otros como vía de realización humana y cristianas."

\subsection{Las rupturas con la Iglesia católica}

Hay también otra creciente minoria formada por quienes se sitúan al margen de la Iglesia católica, a la que consideran comprometida con el sistema o tímida en sus propuestas êticas. En dicha minoría, hay tres grupos bien diferenciados:

\section{a) Conversión a nuevas Iglesias o sectas}

Algunos jóvenes rompen con una Iglesia de la que se habian alejado hacia tiempo y se convierten a alguna de las iglesias evangélicas, pentecostales, escatológicas (como adventistas, testigos, mormones) o de inspiración oriental (como el Hara Krisna) e incluso a sectas extrañas. La conversión se debe a motivos muy distintos, pero no es raro que influya la superación de fallas éticas, a veces vinculadas a la droga, o la superación de la crisis de la subjetividad 
en una sociedad que ha perdido los paradigmas. En tales Iglesias y sectas, los jóvenes conversos hallan un mundo exigente yordenado quellena sus necesidades religiosas y que responde a sus inseguridades con respuestas univocas.

\section{b) El mundo de los eclécticos}

Otros jóvenes, dominados por el difundido relativismo frente a la verdad y críticos de la Iglesia y de toda forma institucional, abrazan una religiosidad que acepta a Dios como referente y como centro de una experiencia subjetiva que se compone, como cóctel, de elementos que proceden de las más diversas tradiciones religiosas, pero que sirven para dar sentido a la propia vida. A veces, los eclécticos forman comunidades o grupos, bastante precarios, en torno a intereses comunes o a otros eclécticos, que, por su personalidad o por la riqueza de experiencias de su vida, han logrado cierto liderazgo.

\section{c) E1 mundo de los escépticos}

Otros jóvenes, bajo el pesa del creciente secularismo de un mundo en el que Dios parece ausente y del aparente sinsentido de una sociedad que tiene los medios para satisfacer las necesidades de los hombres y que genera cada vez mayores diferencias sociales, viven como si Dios no existiera. No son ateos, pues no están seguros de la no exístencia de Dios, pero se declaran agnósticos y olvidan los testimonios sobre Dios que han dado rodos los pueblos de la historia. Parecen estar seguros del sentido totalmente inmanente de esta vida, donde Dios no es necesario para explicar la belleza o el orden del mundo, el sentido del dolor o de la muerte. Si bien algunos perciben tal escepticismo como mutilación y sienten cierta nostalgia de Dios, otros lo viven con naturalidad: están instalados en la relatividad de las cosas y no parecen sentir necesidad de plantearse nuevas preguntas sobre el sentido de la vida. 


\section{Notas}

'Este texto fuc presentado por el autor en el simposio ed Los jóveries y el cambio frente al tercer milenio», organizado por la Facultad de Comunicación de la Universidad de San Martín de Porres (Hotel Maria Angola, 2 de noviembre de 1998). Contamos con la respectiva autocización para su publicación.

Juan Pablo II. Fides et Ratio 48.

'Marzal, Maniael. Estudios de religion campesina. Lima: Pontificia Universidad Católica del Perú, 1977.

"Cortázar, Juan Carlos. aUna aproximación a la experiencia religiosa de los iniversitarios limeriosm. En Serularización, cambio y continuidad en el calolicismo peruano. Lima: Pontificia Universidad Católica del Perú, 1997.

${ }^{5}$ Mujica, Luis. Los zalores en jóvenes universitarios. El caso de los cachimbos 1997-1 y 1997-2. Lima: Pontificia Universidad Católica del Perú, 1998.

"Cortázar, J., op. cit., p. 73.

${ }^{7}$ Ibidem.

"Ibidem, p. 77.

${ }^{\circ}$ Cfr. Mujica, L., op. cit., pp. 36-39.

${ }^{10} \mathrm{Cfr}$. ibidem, pp. 39-53.

"Con fines comparativos, presento información sobre jóvenes mexicanos recaudada por Luengo, Enrique. La religión y los jövenes en México. ¿Et desgasto de nna relación? México: Universidad Iberoamericana, 1993. El autor compara las opiniones religiosas de los estudiantes de la Universidad Tberoamericana, en sus sedes en cuatro ciudades, y las de estudiantes de seis ciudades del pais. Solo transcribo los promedios. a) Sobre Dios: existe y significa para el que responde, $85.9 \%$; existe, pero no significa nada, $6.8 \%$; no existe, $3.4 \%$; no responde, 4\% (cfr. 1993: 243). b) Sentimiento de consuelo y fortaleza en la religión: sí, $82.5 \% ;$ no, $15.1 \%$, no contesta, $2.3 \%$ (cfr. 1993: 244). c) Interés por la religión respecto al de. cinco años antes: mayor, $39.7 \%$; igual, $37.9 \%$; menot, $14.6 \%$; no contesta, $7.8 \%$ (cfr. 1)93: 245). d) ¿Ha cambiado la postura religiosa de los universitarios?: no, $65.8 \%$; si, 22, $8 \%$; no contesta, 11.4\% (cfr. 1993:246).e) Prícticas, actitudes y creencias religiosas de los estudiantes 
la vida: mundo fernenino $(\mathrm{F}), 45.7 \%$, y masculino $(\mathrm{M}) 32.2 \%$; asistencia a servicios religiosos: (F) 37.8\%, (M) 24.2\%, frecuencia de momentos de oración: (F) 44.1\%, (M) 26.7\%; lecrura de la Biblia: (F) $60 \%$, (M) 50\%; justificación de la eutanasia: (E) $51.8 \%$, (M) $\% 7.1$; justificación de las relaciones sexuales prematrimoniales; (F) $62.3 \%$, (M) 76.7\%; justificación del aborto: (F) 36.7\%, (M) 43.8\%; creencia en el alma: (F) $89.9 \%$, (M) $85.4 \%$; creencia en el infierno: (F) $43.2 \%$, (M) 40\% (cfr. 1993:264).

${ }^{12}$ Cfr. Mujica, Li, op, ait., p. 61.

"Cfr. ibidem, pp. 44-45.

${ }^{14}$ González-Carvajal, Luis. Ideas y creencias del bombre artual. Sal Térrea: Santander, 1991.

"Luengo, E, op, ait., p. 278.

"Juan Pablo II. wiscurso en la plaza de San Pedro en Roma, 30 de mayo de 1998\%. Hueltas. Revista de Comanióny Liberación, año II, n. ${ }^{\circ}$, junio de 1998, p. 9.

"Garcia Orso, Luis. "Cómo ser cristiano en el mundo postmoderno?m. Revista Cbristus, n." 8-9, 1993, pp. 45-46, vése p. 179. 